\title{
Development and optimization of microparticles containing a hypoglycemic fraction of calyces from Physalis peruviana
}

\author{
Sandra Milena Echeverry ${ }^{1}$, Ivonne Helena Valderrama ${ }^{1}$, Geison M. Costa ${ }^{2}$, Luis Fernando Ospina-Giraldo ${ }^{1}$, \\ Diana Marcela Aragón ${ }^{1 *}$ \\ ${ }^{1}$ Departamento de Farmacia, Universidad Nacional de Colombia, Bogotá D.C., Colombia. \\ ${ }^{2}$ Departamento de Química, Pontificia Universidad Javeriana, Bogotá D.C., Colombia.
}

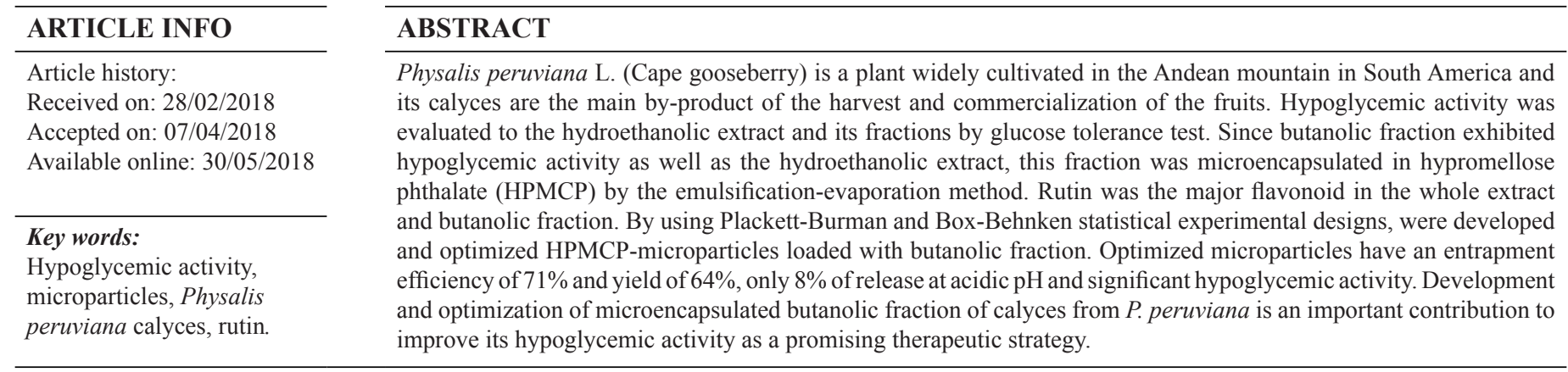

\section{INTRODUCTION}

Physalis peruviana L. (Cape gooseberry) is a plant widely cultivated in the Andean mountain in South America since its fruits are consumed as raw, juices, desserts, jam and processed food (Puente et al., 2011). The plant is an herbaceous, semiupright shrub known for its round, orange-colored fruit which is juicy with a pleasant smell and taste fruit and is enclosed in fivesepal calyx (Novoa et al., 2006). P. peruviana fruits are the second most exported fruit from Colombia whereby its crops exceed the $950 \mathrm{ha} / \mathrm{year}$ and are produced more than 15.000 ton/year of fruits (AGRONET, 2018).

In the recent years, $P$. peruviana has been the subject of many biological studies whence multiple pharmacological activities have been reported. For its leaves has been found antioxidant (Wu et al., 2005) and antidiabetic activity (Kasalia et al., 2013). For its fruits, also has been antidiabetic activity

"Corresponding Author

Diana Marcela Aragón, Departamento de Farmacia, Universidad

Nacional de Colombia, A.A. 14490. Bogotá, Colombia.

E-mail:dmaragonn@unal.edu.co
(Mora et al., 2010) as well as inhibition of intestinal alfa amylase enzyme (Rey et al., 2015), immunomodulatory and cytotoxic activity in HeLa and fibroblast cells (MierGiraldo et al., 2017) and anti-pterygium effect by inhibiting fibroblast growth (Pardo et al., 2008). The calyces have been shown hepatoprotective effect (Toro et al., 2013) and antiinflammatory activity (Toro et al., 2014) related to inhibition of the release of macrophage's proinflammatory cytokines (Martínez et al., 2010) and the inhibition of nitric oxide and prostaglandin E2 (Franco et al., 2014).

$P$. peruviana calyces are the main by-product of the harvest and commercialization of the fruit and the study of its pharmacological properties and chemical composition is a great opportunity to give added value to this important crop. The previous investigation has been reported the presence of sucrose esters (Franco et al., 2014) and hydroxycinnamic acids (Vilaplana et al., 2014) as well as a large content of rutin (Quercetin 3-O-rutinoside) as the main flavonoid (Toro et al., 2014).

Rutin is an $O$-glycosylated flavonoid of which has been reported several biological effects, including antidiabetic activity related to the decreased of glycosylated hemoglobin, C-peptide, 
and malondialdehyde level (Stanley and Kamalakkanan, 2006). In rodents diabetic by streptozotocin administration also has exhibit hepatoprotective effect in (Fernandes et al., 2010). In vitro studies show that rutin potentiates insulin receptor kinase (Hsu et al., 2014) and stimulates both the $\mathrm{Ca}(2+)$ uptake in rat pancreatic islets (Kappel et al., 2013a) and the glucose uptake in the soleus muscle mediated by extracellular calcium and calciumcalmodulin-dependent protein kinase II (CaMKII) (Kappel et al., 2013b). Being rutin the major flavonoid in P. peruviana calyces, these previous reports suggest its potential hypoglycemic/ antidiabetic activity.

In spite of the pharmacological properties of the vegetable extracts, some environmental and systemic condition could degrade the active metabolites of several extracts (Goppel and Franz, 2004; Thakur et al., 2011; Sipahli et al., 2017), mainly $O$-glycosylated flavonoids as rutin (Plaza et al., 2014). For this reason, microencapsulation has been employed for several vegetable extracts since this technique allows a target delivery, protection from enzymes or hydrolytic $\mathrm{pHs}$, masking bitter tastes and improve extracts stability (Singh et al., 2010; Fang and Bhandari, 2010; Santos et al., 2017; Massoung-Bora et al., 2018) resulting in an improvement of the biological activity. Considering the flavonoid rutin as one of the active metabolites of the calyces of $P$. peruviana and its reported instability under acidic conditions, microencapsulation in a $\mathrm{pH}$-sensitive polymer was chosen as a delivery system.

Based on the above described, the aim of this work was to evaluate the hypoglycemic activity of the calyces of $P$. peruviana and to the development and to optimize a microparticulate delivery system that induces an increase on the hypoglycemic activity. For this, initially was determinate the hypoglycemic active fraction of the calyces of $P$. peruviana, then by a Plackett-Burman design was found the significant factors on microencapsulation process of the active fraction and later the microparticles were optimized using a Box-Behnken design. Finally, the hypoglycemic activity of the optimized microparticles was evaluated.

\section{MATERIALS AND METHODS}

\section{Chemicals}

PVA, glucose, and glibenclamide were obtained from Sigma-Aldrich®. Hypromellose phthalate (HPMCP) from Kerry ${ }^{\circledR}$. Dichloromethane, ethyl acetate, butanol, acetic acid, and ethanol were purchased from Panreac $\AA$. Methanol was obtained from Mallinkrodt ${ }^{\circledR}$. All organic solvents were of analytical reagent grade except for methanol which was HPLC grade and water used in all experiments was purified by Direct -Q system (Millipore $\left.{ }^{\circledR}\right)$.

\section{Plant material}

The calyces of Physalis peruviana L. were collected in the region of Granada Cundinamarca (2450 masl), on June 2016. The fresh calyces were dried in an oven drying at a temperature of $40^{\circ} \mathrm{C}$ until constant weight, and ground in a knife mill. One specimen was stored in the Herbarium of the National University of Colombia (COL 512200).

\section{Preparation of $\boldsymbol{P}$. peruviana calyces extract and fractions}

Hydroethanolic extract of $P$. peruviana was obtained by percolation according to previous reports (Cardona et al., 2017). Drug: solvent ratio 1:15 and ethanol $70 \%$ during 72 hours.

The hydroalcoholic extract was submitted to vacuum column chromatography over silica gel (Merck 60), employing solvents in increasing polarity (dichloromethane, ethyl acetate, butanol, and water), yielding three organic fractions and one aqueous fraction. The organic fractions were concentrated by a rotatory evaporator and the aqueous fraction was lyophilized. All fractions were stored at $-4^{\circ} \mathrm{C}$. Ethyl acetate (EFPP), butanol (BFPP) and water/ aqueous fractions (WFPP) were considered for further analysis while dichloromethane was not due to its low yield (less than 1\%).

\section{Rutin quantification}

Quantification of Rutin in the extract, fractions, and microparticles was carried out by HPLC by a methodology previously developed and validated (Cardona et al., 2017). Briefly, A Shimadzu ${ }^{\circledR}$ system (Shimadzu, Tokyo, Japan), consisting of an LC-6AD binary pump, SPD-M20A diode array detector (DAD), SIL-20A HT auto-sampler, DGU-20As in-line degasser, and software LCsolution ${ }^{\circledR}$ were used. The injections $(10 \mu \mathrm{L})$ were carried out on a Phenomenex C-18 $10 \mu \mathrm{m}(150 \times 3.9 \mathrm{~mm})$ column conditioned in a Shimadzu ${ }^{\circledR}$ CTO-20A column oven equilibrated at $35^{\circ} \mathrm{C}$, with detection at $350 \mathrm{~nm}$. The gradient employed was: acidified methanol $(0.5 \%$ acetic acid) (A) with acidified water (0.5\% acetic acid) (B) as follows: $10-50 \% \mathrm{~A}(0-5 \mathrm{~min}), 50 \% \mathrm{~A}$ (5-10 min), 50-80\% A (10-15 min) and 80\% A (15-25 min).

\section{Hypoglycemic activity}

\section{Animals}

The animals were supplied by the Pharmacy Department of the National University of Colombia. Adult female Swiss ICR mice were employed for the evaluation of the hypoglycemic activity (90 animals, 7-10 weeks old, weighting of 30-35 g). The animals were acclimated under constant temperature conditions $\left(22^{\circ} \mathrm{C} \pm 1\right), 12$-hour light/dark cycles, and ad libitum feed and water consumption one week before the bioassay. The bioassays were carried out in accordance with Guide for the Care and Use of Laboratory Animals (1996, published by National Academy Press, 2101 Constitution Ave. NW, Washington, DC 20055, USA). The local Research Ethics Committee (Act 07/2014 Faculty of Science) approved this study.

\section{Glucose tolerance test}

For hypoglycemic activity evaluation of the extract, fractions, and optimized microparticles, it was employed the glucose tolerance test. After $4 \mathrm{~h}$ of fasting, blood glucose levels (BGL) were measured and immediately were orally administered by gavage with each treatment. Thirty minutes after, all the animals were orally administrated with glucose $(2000 \mathrm{mg} / \mathrm{kg})$. BGL was measured (using equipment Accu-Chek Performa ${ }^{\circledR}$ ) before glucose administration and 30, 60, and 120 minutes after. Glibenclamide was administered at $200 \mathrm{mg} / \mathrm{Kg}$, for fraction selection assay, extract and fractions were administered at 500 $\mathrm{mg} / \mathrm{Kg}$ as the maximum dose according to the internal criteria of our research group. For the most active fraction, hypoglycemic activity was evaluated at three different doses $(100,300$, and 500 
$\mathrm{mg} / \mathrm{Kg}$ ). For final test, active fraction was administered at $300 \mathrm{mg} /$ $\mathrm{Kg}$ (according to the results on dose-response evaluation) and the optimized microparticles were administered at equivalent of 300 $\mathrm{mg} / \mathrm{kg}$ of the active fraction. In each group $\mathrm{n}=6$ mice.

\section{Preparation of microparticles}

Due to the low aqueous solubility of the rutin and butanol fraction of the ethanolic extract from calyces of $P$. peruviana (BFPP), the microparticles were prepared by an emulsificationsolvent evaporation method (Aragón et al., 2013). HPMCP and BFPP were dissolved in a mixture of dichloromethane: ethanol $(25: 1)$. This organic phase was mixed with an aqueous phase that content PVA as a stabilizer and emulsified by agitation with Ultra-Turrax ${ }^{\circledR}$ T10 (IKA, Germany) according to the statistical experimental design. Once the emulsion was formed, the organic solvent was removed by constant stirring for 3 hours at room temperature. The obtained suspension was centrifuged at $25000 \mathrm{~g}$ for 8 minutes. The pellet was washed with distilled water 3 times. Finally, the pellet was lyophilized and the microparticles were obtained.

\section{Characterization of the obtained microparticles}

Yield

After the microparticles of each treatment were lyophilized, the microparticles obtained were weighed. The yield of the microencapsulation process was calculated according to equation 1.

$$
\text { Yield }(\%)=\frac{\text { weight of microparticles }}{\text { polymer weight }(\text { HPMPC })+\text { weight of the BFPP }} \times 100
$$

\section{Morphological analysis and particle size}

The shape of the particles obtained was observed by scanning electron microscopy (SEM). The dry microparticles were coated with gold and examined with a scanning electron microscope (FEI QUANTA 200).

Particle size was determinate by analysis of SEM micrographs. Three hundred microparticles of each treatment were observed and measured employed ImageJ (NIH, Bethesda, MD) software.

\section{Entrapment efficacy $(\% E E)$}

EE was evaluated by an indirect method. After the organic phase was evaporated, the aqueous phase was centrifuged for 15 minutes at $12000 \mathrm{~g}$. An aliquot of the supernatant was taken, filtered through $0.22 \mu \mathrm{m}$ membrane and the rutin content was measured by using HPLC.

The percentage entrapment efficacy $(\% \mathrm{EE})$ was calculated by equation 2 :

$$
\mathrm{EE}(\%)=\frac{\text { theoretical amount of rutine-amount of rutin in the supernatant }}{\text { theoretical amount of rutine }} \times 100
$$

\section{In vitro release profile assay}

BPFF release (using rutin as a marker) was evaluated. $1 \mathrm{~mL}$ of the release medium was added to $10 \mathrm{mg}$ of optimized microparticles and aliquots were taken at 60, 120, 180, 240, 320 and 360 minutes for the quantification of rutin by HPLC method previously described. The first 2 hours $\mathrm{pH} 1.2$ solution $(\mathrm{HCl} 0.1$ $\mathrm{N})$ was employed as release medium, after that time the medium was replaced by phosphate buffer $\mathrm{pH}$ 6.8. The release assay was carried out under constant rotary agitation at $37^{\circ} \mathrm{C}$.

\section{Statistical experimental designs}

\section{Plackett-Burman design}

Plackett-Burman design was used to identify the significant factors on the entrapment efficacy of the active fraction by the emulsification-evaporation method. The parameters evaluated were: (A) concentration of the HPMCP; (B) concentration of PVA; (C) Organic phase percentage; (D) HPMCP: BFPP ratio, (E) volume of the aqueous phase; $(F)$ stirring intensity and $(G)$ and stirring time. Each factor was evaluated in two levels: high and low (Table 1). Additionally, yield and particle size were calculated for each treatment.

Table 1: Factors and levels evaluated in Plackett-Burman design for BFPP microencapsulation in HPMCP.

\begin{tabular}{cccc}
\hline & \multirow{2}{*}{ FACTOR } & \multicolumn{2}{c}{ LEVELS } \\
\cline { 3 - 4 } & Concentration of HPMCP (\%) & Low (-1) & High (1) \\
\hline A & Concentration of PVA (\%) & 0.5 & 4 \\
B & Organic phase (\%) & 5 & 1.0 \\
C & HPMCP: BFPP ratio & $3: 1$ & 10 \\
D & Volume of aqueous phase (mL) & 50 & 100 \\
E & Stirring speed (rpm) & 11000 & 14500 \\
F & Stirring time (min) & 2 & 5 \\
G & & & \\
\hline
\end{tabular}

\section{Optimization of BFPP microencapsulation in HPMCP}

\section{Box-Behnken design (BBD)}

Once were identified the factors that influence the entra efficiency of the active fraction microencapsulation in HPMCP, the more suitable levels where chosen and Box-Behnken response surface methodology (RSM) was employed to find the optimal conditions to BFPP entrapment efficacy. For the experimental design, three factors (independent variable) were assayed at three levels: low $(-1)$, medium $(0)$ and high $(+1)$. The number of experiments $(\mathrm{N})$ required for the development of BBD was defined as $\mathrm{N}=2 k^{(k-1)}+C_{0}$, (where $k$ is number of factors and $C_{0}$ is the number of central points). For this research, the BBD used was composed of 15 experiments, which 12 treatments and 3 central points (table 2).

\section{Statistical analysis}

The software Minitab ${ }^{\circledR}$ (version 17 State College, PA, USA) was used to propose the experimental designs, data analysis, and model building of the optimization process. GraphPad Prism $\mathbb{R}$ software (version 7, San Diego, CA, USA) was employed for analysis data of glucose tolerance test. 


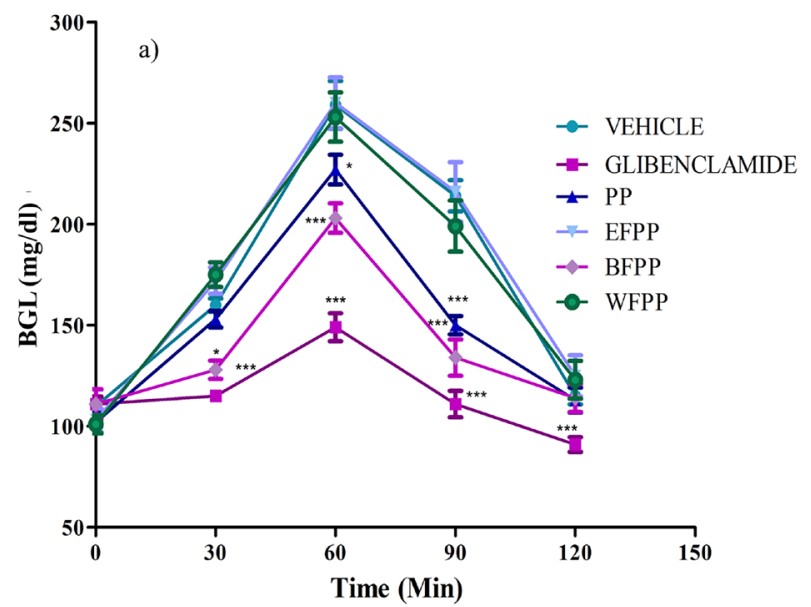

b)

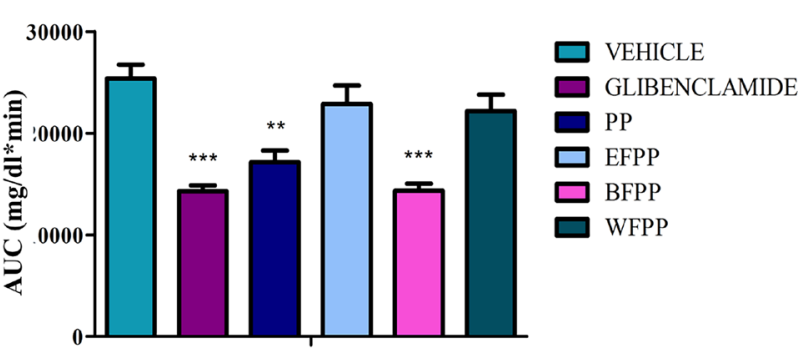

Fig. 1: Hypoglycemic activity of extract and fractions of calyces from P. peruviana. PP: Hydroethanolic extract of calyces from P. peruviana, EFPP: Ethyl Acetate fraction, BFPP: Butanolic fraction, WFPP: Aqueous fraction. Glibenclamide $200 \mathrm{mg} / \mathrm{Kg}$, Extract and fractions $500 \mathrm{mg} / \mathrm{Kg}$. Data are expressed as mean \pm SEM $\mathrm{n}=6$ animals per group. (a) Two-way ANOVA post-test Bonferroni *p $<0.05 ; *$ p $<0.01$ and $* * * p<0.001$ respect to vehicle group. (b) One-way ANOVA post-test Dunnet $* * \mathrm{p}<0.01$ and $* * * \mathrm{p}<0.001$ respect to vehicle group.

\section{RESULT AND DISCUSSION}

\section{The content of rutin in $P$. peruviana calyces extract and fractions}

According to HPLC-DAD quantification, rutin content in the obtained extract was $14.54 \mu \mathrm{g} / \mathrm{mg}$ dry extract. In the fractions obtained, rutin was only found in the butanolic fraction $(22.00 \mu \mathrm{g} / \mathrm{mg}$ dry extract).

Table 2: Plackett- Burman experimental design to BPFF microencapsulation with HPMCP.

\begin{tabular}{|c|c|c|c|c|c|c|c|c|c|}
\hline \multirow{2}{*}{ RUN } & \multicolumn{7}{|c|}{ FACTOR } & \multicolumn{2}{|c|}{ RESPONSE VALUE } \\
\hline & $\mathbf{A}$ & B & $\mathbf{C}$ & D & $\mathbf{E}$ & $\mathbf{F}$ & G & EE (\%) & YIELD (\%) \\
\hline 1 & -1 & -1 & -1 & -1 & -1 & -1 & -1 & 68.1 & 36.8 \\
\hline 2 & 1 & -1 & 1 & -1 & 1 & -1 & 1 & 61.7 & 62.1 \\
\hline 3 & 1 & 1 & -1 & 1 & -1 & 1 & -1 & 59.3 & 47.6 \\
\hline 4 & -1 & 1 & 1 & -1 & 1 & -1 & 1 & 58.3 & 39.6 \\
\hline 5 & 1 & -1 & 1 & 1 & -1 & 1 & -1 & 57.6 & 52.4 \\
\hline 6 & 1 & 1 & -1 & 1 & 1 & -1 & 1 & 59.4 & 42.9 \\
\hline 7 & -1 & 1 & 1 & -1 & 1 & 1 & -1 & 56.5 & 22.0 \\
\hline 8 & -1 & -1 & -1 & 1 & -1 & 1 & 1 & 74.6 & 31.0 \\
\hline
\end{tabular}

Hypoglycemic activity of $P$. peruviana calyces extract and fractions

The hypoglycemic effect was evaluated by glucose tolerance test which is often employed as screening to several plant extracts. This test allows following the BGL at specific points on the time after an oral glucose overload as well as the global effect on time by the area under the curve (AUC $\mathrm{mg} / \mathrm{dl}^{*} \mathrm{~min}$ ) analysis (Andrikopoulos et al., 2008). Hypoglycemic activity of the extract and fractions of calyces form $P$. peruviana by glucose tolerance test is present in Figure 1. Is possible to note that hydroethanolic extract of $P$. peruviana has a significant hypoglycemic effect and this activity is maintained only by the butanolic fraction
(BFPP). In the first 60 minutes, the BGL decrease by BFPP is even greater than those presented by the whole extract. This fact suggests that the active hypoglycemic compounds of calyces from $P$. peruviana extract are in the butanolic fraction similar to reported to other plants (Borar et al., 2011; Toma et al., 2015; Ibrahim and Islam, 2017). According to previous reports that identify rutin as major flavonoid in the hydroethanolic extract of calyces from P. peruviana and the evidence of hypoglycemic effect of this compound and its role in the glucose homeostasis by different mechanisms like secretagogue of insulin and stimulating of glucose uptake in muscle (Kappel et al., 2013a; b; c), is possible to relate this flavonoid to the observed effect.

Before microencapsulation, a dose-response study of BFPP was carried out (Figure 2). The results suggest that the hypoglycemic activity of the BFPP is dose-dependent and that $300 \mathrm{mg} / \mathrm{Kg}$ is the lowest active dose (in the range studied). Based on these results, BFPP was chosen to develop a microparticulate system as a delivery system with hypoglycemic activity.

\section{Microencapsulation of BFPP in HPMCP}

Rutin is extremely labile to acidic hydrolysis, as well as the other $O$-glycosylated flavonoid. This fact as well as its poor aqueous solubility, contribute to its low bioavailability (Sharma et al., 2013) and therefore to a limited pharmacological activity. Considering rutin as one of the secondary metabolites responsible for the hypoglycemic effect presented by BFPP, polymer hypromellose phthalate (HPMCP) was chosen for microparticles development. HPMCP is $\mathrm{pH}$ sensitive polymer soluble at $\mathrm{pH}$ higher than 5.5 widely employed in formulations of drugs labile to gastric conditions (Qi and Ping, 2004; Rassu et al., 2014; Singh et al., 2015).

For the development of HPMCP BFPP-loaded microparticles, initially was determine the factors that influenced the entrapment efficacy of the rutin (as marker) content in BFPP. For this, it was using the Plackett-Burman experimental design which has been successfully employed as screening design for formulation development (Vanaja and Shobha, 2007). 


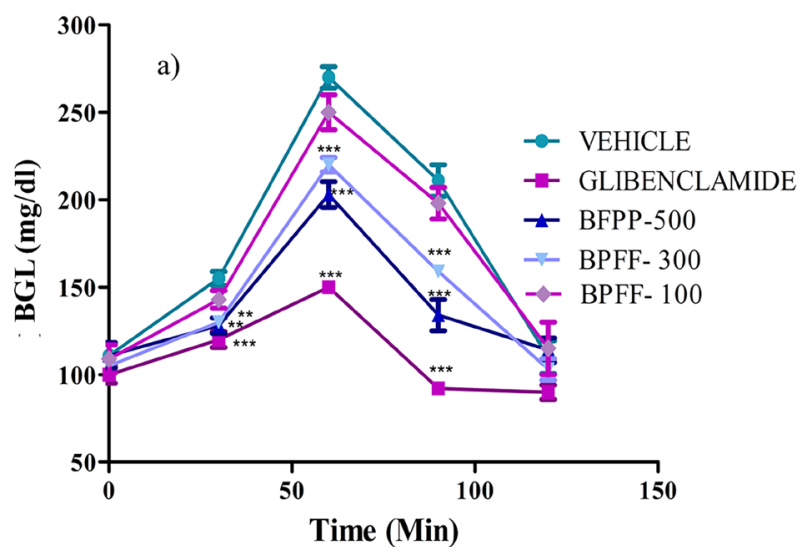

b)

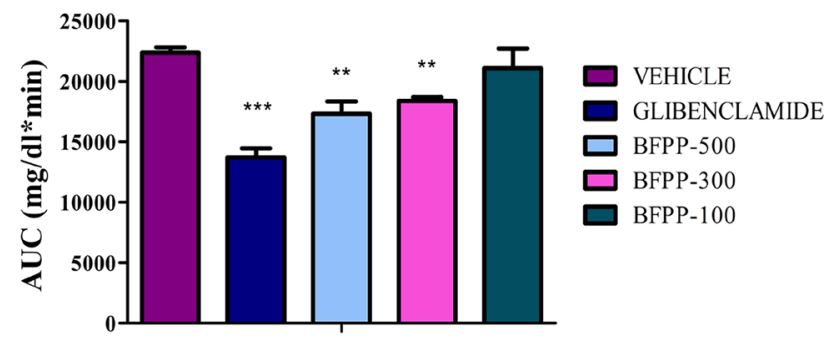

Fig. 2: Hypoglycemic activity of the butanolic fraction of calyces from P. peruviana. BFPP-500: Butanolic fraction dose 500 mg/Kg, BFPP-300: Butanolic fraction dose $300 \mathrm{mg} / \mathrm{Kg}$, BFPP-100: Butanolic fraction dose $100 \mathrm{mg} / \mathrm{Kg}$ Data are expressed as mean $\pm \mathrm{SEM} \mathrm{n}=6$ animals per group. (a) Two-way ANOVA post-test Bonferroni * $\mathrm{p}$ $<0.05 ; * * \mathrm{p}<0.01$ and $* * * \mathrm{p}<0.001$ respect to vehicle group. (b) One-way ANOVA post-test Dunnet $* * \mathrm{p}<0.01$ and $* * * \mathrm{p}<0.001$ respect to vehicle group.

For this, seven factors were evaluated at two levels (Table 1) which were selected based on previous results of our research group. Yield values ranged between 31 and $62 \%$ and all were considering microparticles (sizes between 1 and $7 \mu \mathrm{m}$ ).

According to the ANOVA analysis (Table 3), the model was significant $(p<0.05)$ to entrapment efficiency of BPFF. For the statistical analysis, only the significant factors were employed while the other factors were grouped in the error term. The concentration of HPMCP (\%), concentration of PVA (\%) and organic phase (\%) were the factors with the greatest effect on entrapment efficacy of BPFF. These factor at their low level had a positive effect on the response variable and it was further optimized by Box-Behnken design.

Table 3: Analysis of variance (ANOVA) for Placket-Burmann statistical design to entrapment efficacy (\%) of BPFF in HPMCP microparticles.

\begin{tabular}{cccccc}
\hline Source & df & SS & MS & F Value & P Value \\
\hline Model & 5 & 270.619 & 54.124 & 26.59 & 0.037 \\
Concentration of HPMCP & 1 & 48.315 & 48.315 & 23.74 & 0.040 \\
Concentration of PVA & 1 & 102.113 & 102.113 & 50.16 & 0.019 \\
Organic phase & 1 & 93.22 & 93.22 & 45.8 & 0.021 \\
Volume of aqueous phase & 1 & 7.784 & 7.784 & 3.82 & 0.19 \\
Stirring speed & 1 & 26.92 & 26.92 & 13.22 & 0.068 \\
Error & 2 & 4.071 & 2.036 & & \\
Total & 7 & 274.69 & & & \\
\hline
\end{tabular}

\section{Optimization}

According to Plackett-Burman design, for optimization four factors were kept constant HPMCP: BFPP ratio (3:1), volume of aqueous phase $(100 \mathrm{~mL})$, stirring speed $(14500 \mathrm{rpm})$ and stirring time (5 min). The concentration of HPMCP (\%), concentration of PVA (\%) and organic phase (\%) were optimized at three levels (Table 4).

Experimental statistical designs have been widely used for microencapsulation process (Paulo and Santos, 2017) for both, screening and optimization. Box-Behnken are experimental designs for response surface methodology successfully employed for optimization of process and formulation of drug delivery systems. The Box-Behnken experimental design employed in this study consisted of 15 treatments, three of them were central points (Table 5). According to ANOVA, the F-value of the model (15.15) implies that the model was significant $(<0.05)$ (Table 6). In this design, only the concentration of PVA was a significant factor as well as the interactions PVA $x$ PVA and organic phase $\mathrm{x}$ organic phase. None of the 2-way interactions were significant in the experimental design. The analysis of variance calculated for the coefficient of determination $\mathrm{R}^{2}$ and coefficient of determination adjusted values of 0.9646 and 0.9009 respectively. Lack of fit is not significant which indicates that the model fits well with the data. Response surface plots are shown in Figure 3.

Table 4: Factors and levels evaluated in Box-Behnken design to BPFF microencapsulation with HPMCP.

\begin{tabular}{ccccc}
\hline & \multirow{2}{*}{ FACTOR } & \multicolumn{3}{c}{ LEVELS } \\
\cline { 3 - 5 } & & Low (-1) & Medium (0) & High (1) \\
\hline A & Concentration of HPMCP (\%) & 1 & 1.5 & 2 \\
B & Concentration of PVA (\%) & 0.3 & 0.4 & 0.5 \\
C & Organic phase (\%) & 3 & 4 & 5 \\
\hline
\end{tabular}

The model proposed a polynomial equation (Equation 3) for predict the entrapment efficacy of BFPP.

$\mathrm{EE}=-248.4+1007 \mathrm{~A}+138.7 \mathrm{~B}-12.0 \mathrm{C}-1027 \mathrm{~A} \times \mathrm{A}-44.48 \mathrm{~B} \times$ $\mathrm{B}+1.73 \mathrm{C} \times \mathrm{C}-4.8 \mathrm{~A} \times \mathrm{B}-7.8 \mathrm{~A} \times \mathrm{C}+0.32 \mathrm{~B} \times \mathrm{C}$,

where $\mathrm{EE}=$ Entrapment efficacy $(\%) ; \mathrm{A}=$ Concentration of PVA $(\%)$; $\mathrm{B}=$ Concentration of HPMCP (\%); C = Organic phase (\%).

Finally, Minitab 17 software was employed to determine the optimum values of the factors for maximum entrapment efficiency as follows: $1.54 \%$ for Concentration of HPMCP; $0.47 \%$ for a concentration of PVA and $3 \%$ for organic phase. The predicted value of encapsulation efficiency was $72.5 \%$. To verify the prediction of the model, six batches of microparticles of BFPP were prepared with the optimal conditions. The experimental value of encapsulation efficiency was $71.3 \pm 0.27 \%$; yield of 64.1 $\%$ and $4.3 \mu \mathrm{m}$ as average size. Experimental entrapment efficiency was not significantly different from the predicted value. 


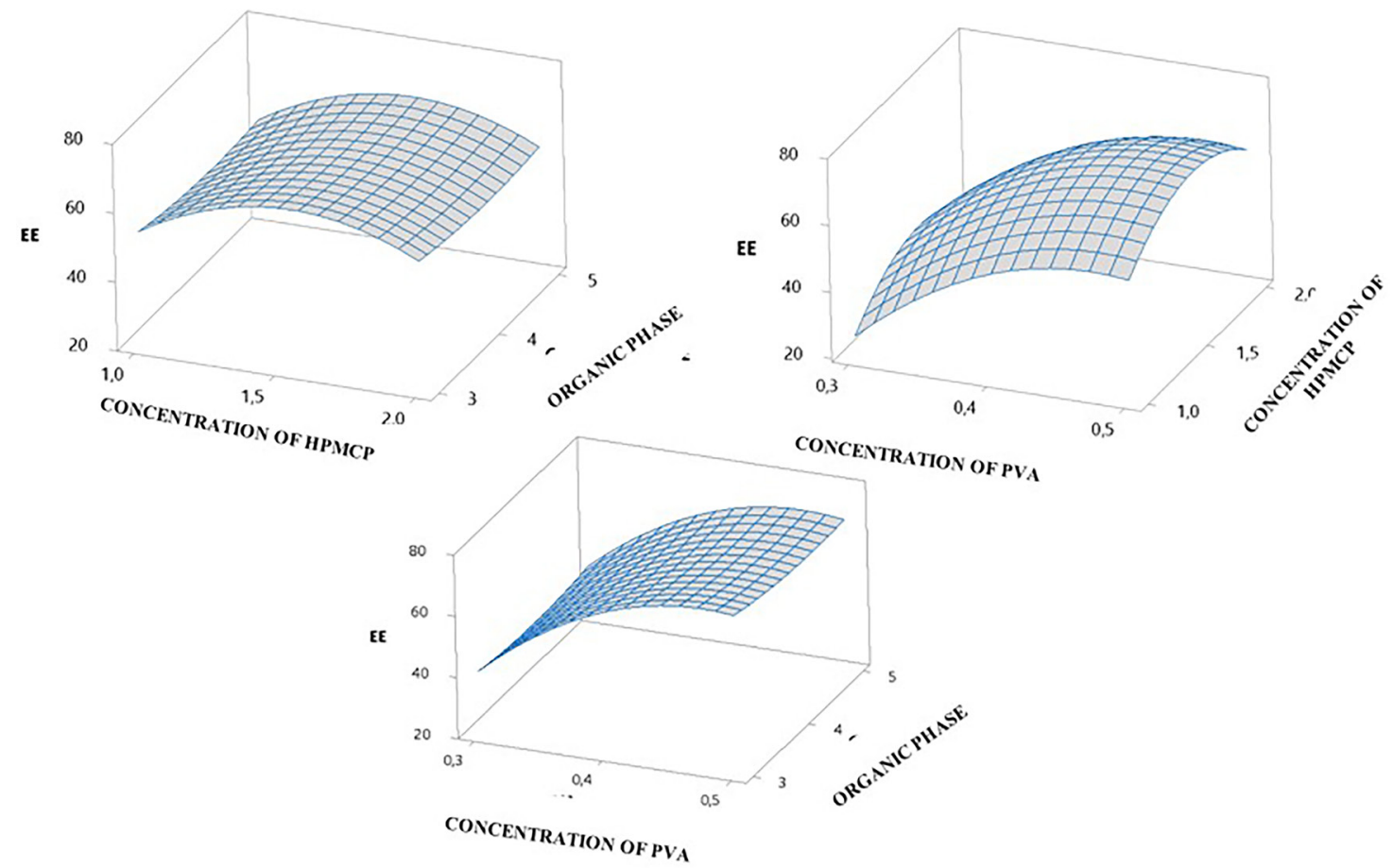

Fig. 3: Response surface plots showing relative effects of different process parameters on the entrapment efficacy of BFPP on HPMCP microparticles. EE: Entrapment efficacy.

Table 5: Box-Behnken experimental design to BPFF microencapsulation with HPMCP.

\begin{tabular}{ccccccc}
\hline \multirow{2}{*}{ StdOrder } & \multirow{2}{*}{ RunOrder } & \multicolumn{3}{c}{ FACTOR } & \multicolumn{2}{c}{ RESPONSE VALUE } \\
\cline { 2 - 7 } & & A & B & C & EE (\%) & YIELD (\%) \\
\hline $\mathbf{1 4}$ & 1 & 0 & 0 & 0 & 64.0 & 51.9 \\
$\mathbf{6}$ & 2 & 1 & 0 & -1 & 75.0 & 32.3 \\
$\mathbf{1 2}$ & 3 & 0 & 1 & 1 & 56.5 & 39.9 \\
$\mathbf{1}$ & 4 & -1 & -1 & 0 & 29.3 & 45.6 \\
$\mathbf{1 3}$ & 5 & 0 & 0 & 0 & 64.1 & 48.2 \\
$\mathbf{5}$ & 6 & -1 & 0 & -1 & 37.2 & 36.7 \\
$\mathbf{1 5}$ & 7 & 0 & 0 & 0 & 64.2 & 50.0 \\
$\mathbf{8}$ & 8 & 1 & 0 & 1 & 72.3 & 62.5 \\
$\mathbf{4}$ & 9 & 1 & 1 & 0 & 55.6 & 65.5 \\
$\mathbf{7}$ & 10 & -1 & 0 & 1 & 37.7 & 19.2 \\
$\mathbf{2}$ & 11 & 1 & -1 & 0 & 52.3 & 76.7 \\
$\mathbf{1 1}$ & 12 & 0 & -1 & 1 & 50.8 & 50.7 \\
$\mathbf{9}$ & 13 & 0 & -1 & -1 & 53.3 & 38.2 \\
$\mathbf{1 0}$ & 14 & 0 & 1 & -1 & 58.3 & 39.0 \\
$\mathbf{3}$ & 15 & -1 & 1 & 0 & 33.6 & 36.4 \\
\hline
\end{tabular}

Release profile was evaluated for the optimized microparticles (Figure 4) in order to verify the gastroprotective effect of the HPMCP polymer. In the first 120 minutes at $\mathrm{pH} 1.2$, similar to gastric $\mathrm{pH}$, only $6.5 \%$ of BFPP (measured as rutin) was released. This release can be explained by burst effect of BFPP located on the surface of the microparticles (Rizi et al.,
2011). Once the release medium change to $\mathrm{pH}$ 6.8, BFPP release increase until reaching the $100 \%$ at $360 \mathrm{~min}$ (6 hours). This profile is similar to those reported to other HPMCP delivery systems (Prasad et al., 2013; Chung et al., 2014) suggesting an effective acid $\mathrm{pH}$ protection to BFPP.

Table 6: Analysis of variance (ANOVA) for Box-Behnken statistical design to entrapment efficacy (\%) of BPFF in HPMCP microparticles.

\begin{tabular}{|c|c|c|c|c|c|}
\hline SOURCE & DF & SS & MS & F Value & p Value \\
\hline Model & 9 & 2601.94 & 289.1 & 15.15 & 0.004 \\
\hline Linear & 3 & 1773.6 & 591.2 & 30.98 & 0.001 \\
\hline Concentration of PVA & 1 & 1726.08 & 1726.08 & 90.44 & 0.000 \\
\hline Concentration of HPMCP & 1 & 42.07 & 42.07 & 2.2 & 0.198 \\
\hline Organic phase & 1 & 5.45 & 5.45 & 0.29 & 0.616 \\
\hline Square & 3 & 825.53 & 275.18 & 14.42 & 0.007 \\
\hline $\mathrm{PVA} \times \mathrm{PVA}$ & 1 & 389.42 & 389.42 & 20.4 & 0.006 \\
\hline Polymer $\times$ Polymer & 1 & 456.61 & 456.61 & 23.92 & 0.005 \\
\hline $\begin{array}{c}\text { Organic phase } \times \text { Organic } \\
\text { phase }\end{array}$ & 1 & 11.11 & 11.11 & 0.58 & 0.480 \\
\hline 2-Way interaction & 3 & 2.80 & 0.93 & 0.05 & 0.984 \\
\hline PVA $\times$ Polymer & 1 & 0.23 & 0.23 & 0.01 & 0.917 \\
\hline PVA $\times$ Organic phase & 1 & 2.46 & 2.46 & 0.13 & 0.734 \\
\hline Polymer $\times$ Organic phase & 1 & 0.11 & 0.11 & 0.01 & 0.944 \\
\hline Error & 5 & 95.43 & 19.09 & & \\
\hline Lack of fit & 3 & 95.41 & 31.8 & 4905.02 & 0.056 \\
\hline Pure Error & 2 & 0.02 & 0.01 & & \\
\hline Total & 14 & 2697.37 & & & \\
\hline
\end{tabular}




\section{Hypoglycemic activity of BFPP free and microencapsulated}

The effect of the microencapsulation on the hypoglycemic activity of BFPP was evaluated by the glucose tolerance test (Figure 5).

Microencapsulated BFPP exhibit higher decrease of the BGL that free BFPP. And in spite of that difference was statistically significant only at $\mathrm{t}=60 \mathrm{~min}(\mathrm{p}<0.05)$, the AUC results show that over time, there is a greater BGL decrease in the animals treated that microencapsulated BFPP that those treated with free BFPP ( $p$
$<0.05)$ similar to previous reports to other hypoglycemic extracts and compounds (Chime et al., 2014; Sharma and Mazumder, 2014; Zhao et al., 2014). These results evidence the influence of microparticulate delivery systems on the pharmacological activity since it allows overcome some problems of several drugs as poor solubility and $\mathrm{pH}$ or enzymatic degradation, among others (Singh et al., 2010). This fact has been reported for different drugs encapsulated with HPMCP as insulin, tymol, and vaccines (Qi and Ping, 2004; Rassu et al., 2014; Singh et al., 2015).

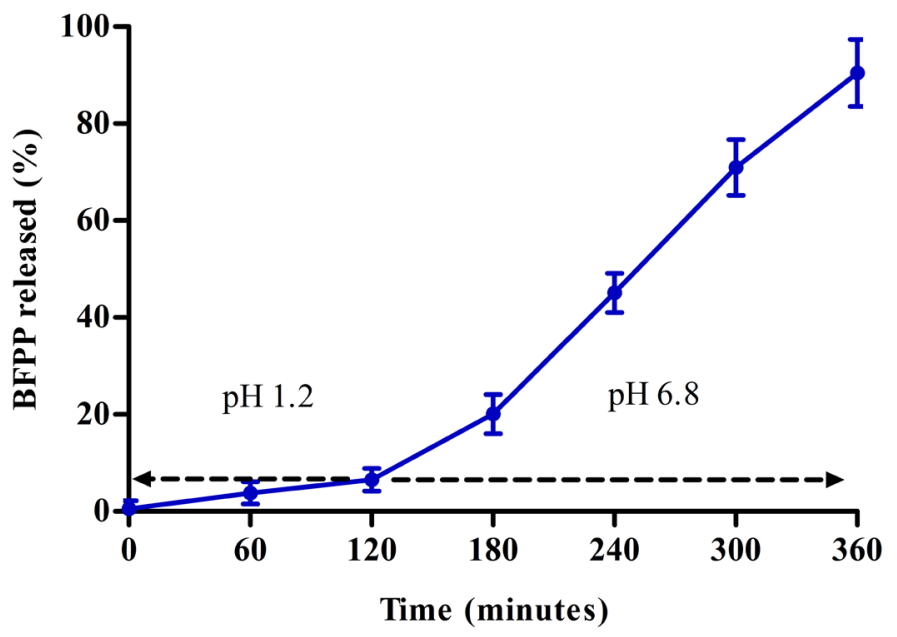

Fig. 4: BFPP release profile from HPMCP microparticles. Data are expressed as mean $\pm \mathrm{SEM} n=3$ batches. Release percentage was evaluated considering rutin in the release medium and rutin contained in BFPP microencapsulated.

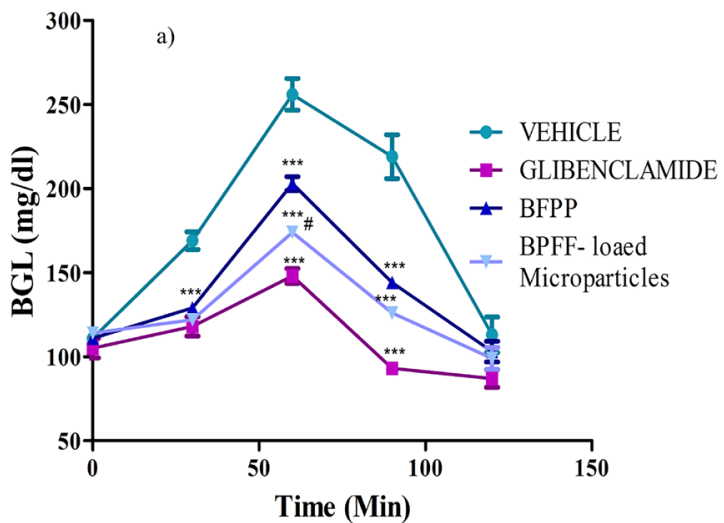

b)

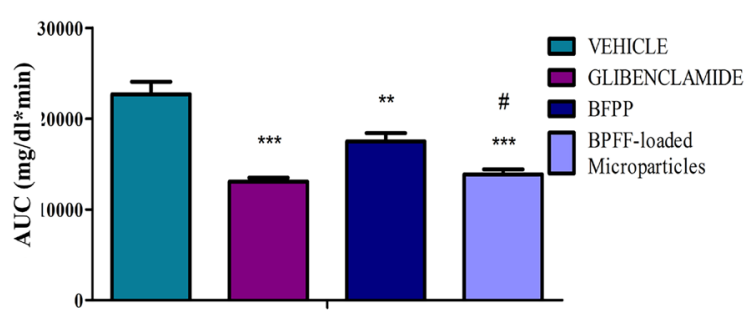

Fig. 5: Hypoglycemic activity of BFPP free and microencapsulated. BFPP: Butanolic BFPP-loaded microparticles: Microparticles of HPMCP containing BFPP. Glibenclamide $200 \mathrm{mg} / \mathrm{Kg}$, BFPP $300 \mathrm{mg} / \mathrm{Kg}$, BFPP-loaded microparticles equivalent to $300 \mathrm{mg} / \mathrm{Kg}$ of BFPP. Data are expressed as mean \pm SEM $\mathrm{n}=6$ animals per group. (a) Two-way ANOVA post-test Bonferroni $* \mathrm{p}<0.05 ; * * \mathrm{p}<0.01$ and $* * * \mathrm{p}<0.001$ respect to vehicle group, \#p $<0.05$ respect to BFPP. (b) One-way ANOVA post-test Dunnet $* * \mathrm{p}<0.01$ and $* * * \mathrm{p}<0.001$ respect to vehicle group, $\# \mathrm{p}<0.05$ respect to BFPP.

Considering the flavonoid rutin as one of the compounds responsible of hypoglycemic activity of BFPP and taking into account its instability at acidic conditions, development, and optimization of HPMCP BFPP-loaded microparticles is an important contribution to improve the hypoglycemic activity of the butanolic fraction of calyces from $P$. peruviana.

\section{CONCLUSIONS}

In this study, it was demonstrated the hypoglycemic activity of the hydroethanolic extract of calyces from P. peruviana.
Its butanolic fraction, rich in rutin, identified as the most active. By using statistical experimental designs were developed and optimized HPMCP BFPP-loaded microparticles that improved the hypoglycemic effect of butanolic fraction of calyces from $P$. peruviana. The developed microparticles are a promising delivery system of a hypoglycemic fraction from calyces of $P$. peruviana.

\section{ACKNOWLEDGMENT}

The authors are grateful for the financial support provided by the Fondo Nacional de Financiamiento para la 
Ciencia, la Tecnología y la Innovación, Francisco José de Caldas, contract No. 677-2014.

\section{CONFLICT OF INTEREST}

The authors declare that they have no conflict of interest.

\section{REFERENCES}

AGRONET-Network of information and strategic communication of the agricultural sector in Colombia 2018. Available at http://www.agronet.gov.co/ (accessed 5 February 2018).

Aragón DM, Rosas JE, Martínez F. Relationship between the solution thermodynamic properties of naproxen in organic solvents and its release profiles from PLGA microspheres. J Microencapsul. 2013; 3:218224

Andrikopoulos S, Blair AR, Deluca N, Fam BC, Proietto J. Evaluating the glucose tolerance test in mice. Am J Physiol Endocrinol Metab. 2008; 295:E1323-E1332.

Borar S, Punia P, Kalia AN. Antioxidant potential of n-butanol fraction from extract of Jasminum mesnyi Hance leaves. Indian J Exp Biol. $2011 ; 49: 39-43$

Cardona MI, Toro RM, Costa GM, Ospina LF, Castellanos L, Ramos FA, Aragón DM. Influence of extraction process on antioxidant activity and rutin content in Physalis peruviana calyces extract. J Appl Pharm Sci. 2017; 7:164-168.

Chime SA, Onyishi IV, Ugwoke PU, Attama AA. Evaluation of the properties of Gongronema latifolium in phospholipon 90h based solid lipid microparticles (SLMs): An Antidiabetic Study. J Diet Suppl. 2014; 11:7-18.

Chung JH, Lee SJ, Chung JO, Oh YJ, Hwang JA, Kim YK, Shim SM. Effect of hydroxypropyl methyl cellulose phthalate coating on digestive stability and intestinal transport of green tea catechins. J Integr Med. 2014; 3:34-37.

Fang Z, Bhandari B. Encapsulation of polyphenols - a review. Trends Food Sci Technol. 2010; 21:510-523.

Fernandes AA, Novelli EL, Okoshi K, Okoshi MP, Di Muzio BP, Guimarães JF, Fernandes AJ. Influence of rutin treatment on biochemical alterations in experimental diabetes. Biomed Pharmacother. 2010; 64:214219

Franco LA, Ocampo YC, Gómez HA, De la Puerta R, Espartero JL, Ospina LF. Sucrose esters from Physalis peruviana calyces with antiinflammatory activity. Planta Med. 2014; 80:1605-1614.

Goppel M, Franz G. Stability control of valerian ground material and extracts: a new HPLC method for the routine quantification of valerenic acids and lignans. Pharmazie. 2004; 59:446-452.

Hsu CY, Shih HY, Chia YC, Lee CH, Ashida H, Lai YK, Weng CF. Rutin potentiates insulin receptor kinase to enhance insulin-dependent glucose transporter 4 translocation. Mol Nutr Food Res. 2014; 58:11681176.

Ibrahim MA, Islam MS. Effects of butanol fraction of Ziziphus mucronata root ethanol extract on glucose homeostasis, serum insulin and other diabetes-related parameters in a murine model for type 2 diabetes. Pharm Biol. 2017; 55:416-422.

Kappel VD, Frederico MJS, Postal BG, Mendes CP, Cazarolli LH, Silva FRMB. The role of calcium in intracellular pathways of rutin in rat pancreatic islets: Potential insulin secretagogue effect. Eur J Pharmacol 2013a; 702:264-268.

Kappel VD, Cazarolli LH, Pereira DF, Postal BG, Zamoner A, Reginatto FH, Silva FRJ. Involvement of GLUT-4 in the stimulatory effect of rutin on glucose uptake in rat soleus muscle. Pharm Pharmacol. 2013b; 65:1179-86.

Kappel VD, Zanatta L, Postal BG, Silva FRMB. Rutin potentiates calcium uptake via voltage-dependent calcium channel associated with stimulation of glucose uptake in skeletal muscle. Arch Biochem Biophys. 2013c; 532:55-60.

Kasalia FM, Kadima JN, Mpiana PT, Ngbolua K, Tshibangu DS. Assessment of antidiabetic activity and acute toxicity of leaf extracts from Physalis peruviana L. in guinea-pig. Asian Pac J Trop Biomed. 2013; 3:841-846.

Martínez W, Ospina LF, Granados D, Delgado G. In vitro studies on the relationship between the anti-inflammatory activity of Physalis peruviana extracts and the phagocytic process. Immunopharmacol Immunotoxicol. 2010; 32:63-73.

Massoung-Bora AF, Ma S, Li X, Liu L. Application of microencapsulation for the safe delivery of green tea polyphenols in food systems: Review and recent advances. Food Res Int. 2018; 105:241-249.

Mier-Giraldo H, Díaz-Barrera LE, Delgado-Murcia LG, ValeroValdivieso MF, Caéz-Ramírez G. Cytotoxic and immunomodulatory potential activity of Physalis peruviana fruit extracts on cervical cancer (HeLa) and fibroblast (L929) cells. J Evid Based Complementary Altern Med. 2017; 22:777-787.

Mora AC, Aragón DM, Ospina LF. Effects of Physalis peruviana fruit extract on stress oxidative parameters in streptozotocin-diabetic rats Lat Am J Pharm. 2010; 29:1132-1136.

Novoa RH, Bojaca M, Galvis JA, Fischer G. Fruit maturity and calyx drying influence post-harvest behavior of Cape gooseberry (Physalis peruviana L.) stored at $12^{\circ} \mathrm{C}$. Agron Colomb. 2006; 24:77-86.

Pardo JM, Espinosa L, Fontanilla MR, Ospina LF. Determining the pharmacological activity of Physalis peruviana fruit juice on rabbit eyes and fibroblast primary cultures. IOVS. 2008; 49:3074-3079.

Paulo F, Santo L. Design of experiments for microencapsulation applications: A review. Mater Sci Eng C. 2017; 77:1327-1340.

Plaza M, Pozzo T, Liu J, Ara KZG, Turner C, Karlsson EN Substituent effects on in vitro antioxidizing properties, stability, and solubility in flavonoids. Agric Food Chem. 2014; 62:3321-3333.

Prasad MB, Vidyadhara S, Sasidhar RLC, Balakrishna T, Trilochani P. Development and evaluation of diltiazem hydrochloride controlled-release pellets by fluid bed coating process. J Adv Pharm Technol Res. 2013; 4:101-107.

Puente LA, Pinto-Muñoz CA, Castro ES, Cortés M. Physalis peruviana Linnaeus, the multiple properties of a highly functional fruit: A review. Food Res Int. 2011; 44:1733-1740.

Qi R, Ping QN. Gastrointestinal absorption enhancement of insulin by administration of enteric microspheres and SNAC to rats. J Microencapsul. 2004; 21:37-45.

Rassu G, Nieddu M, Bosi P, Trevisi P, Colombo M, Priori D, Manconi P, Giunchedi P, Gavini E, Boatto G. Encapsulation and modifiedrelease of thymol from oral microparticles as adjuvant or substitute to current medications. Phytomedicine. 2014; 21:1627-1632.

Rey DP, Ospina LF, Aragón DM. Inhibitory effects of an extract of fruits of Physalis peruviana on some intestinal carbohydrases. Rev Colomb Cienc Quim Farm. 2015; 44:72-89.

Rizi K, Green RJ, Khutoryanskaya O, Donaldson M, Williams AC. Mechanisms of burst release from $\mathrm{pH}$-responsive polymeric microparticles. J Pharm Pharmacol. 2011; 63:1141-1155.

Santos SS, Rodrigues LM, Costa SC, Madronac GS. Food Antioxidant compounds from blackberry (Rubus fruticosus) pomace: Microencapsulation by spray-dryer and $\mathrm{pH}$ stability evaluation Packaging and Shelf Life. 2017; In press: available https://doi.org/10.1016/j. fps1.2017.12.001.

Sharma S, Ali A, Ali J, Sahni JK, Baboota S. Rutin: therapeutic potential and recent advances in drug delivery. Expert Opin Investig Drugs. $2013 ; 22: 1-17$

Sharma VK, Mazumder B. Gastrointestinal transition and antidiabetic effect of Isabgol husk microparticles containing gliclazide. Int $\mathrm{J}$ Biol Macromol. 2014; 66:15-25.

Singh MN, Hemant KS, Ram M, Shivakumar HG. Microencapsulation: A promising technique for controlled drug delivery. Res Pharm Sci. 2010; 5:65-77.

Singh B, Maharjan S, Jiang T, Kang S, Choi Y, Cho C. Attuning hydroxypropyl methylcellulose phthalate to oral delivery vehicle for effective and selective delivery of protein vaccine in ileum. Biomaterial. 2015; 59:144-159. 
Sipahli S, Mohanlall V, Mellem JJ. Stability and degradation kinetics of crude anthocyaninextracts from H. sabdariffa. Food Sci Technol. 2017; 37:209-215.

Stanley P, Kamalakkannan N. Rutin improves glucose homeostasis in streptozotocin diabetic tissues by altering glycolytic and gluconeogenic enzymes. J Biochem Mol Toxicol. 2006; 20:96-102.

Thakur L, Ghodasra U, Patel N, Dabhi M. Novel approaches for stability improvement in natural medicines. Pharmacognosy Reviews. $2011 ; 5: 48-54$.

Toma A, Makonnen E, Mekonnen Y, Debella A, Adisakwattana S. Antidiabetic activities of aqueous ethanol and n-butanol fraction of Moringa stenopetala leaves in streptozotocin-induced diabetic rats. BMC Complement Altern Med. 2015; 18:1-8.

Toro RM, Aragón DM, Ospina LF. Hepatoprotective effect of calyces extract of Physalis peruviana on hepatotoxicity induced by $\mathrm{CCl}_{4}$ in Wistar rats. Vitae. 2013; 20:125-132.

Toro RM, Aragón DM, Ospina LF, Ramos F, Castellanos L. Phytochemical analysis, antioxidant and anti-inflammatory activity of calyces from Physalis peruviana. Nat Prod Commun. 2014; 9:1-2.
Vanaja K, Shobha RH. Design of experiments: concept and applications of Plackett Burman design. Clin Res Regul Aff. 2007; 24:1-23.

Vilaplana A, Baena N, Villaño D, Speisky H, García-Viguera C, Moreno D. Evaluation of Latin-American fruits rich in phytochemicals with biological effects. J Funct Foods. 2014; 7:599-608.

Wu SJ, Ng LT, Huang YM, Lin DL, Wang SS, Huang SN, Lin CC. Antioxidant activities of Physalis peruviana. Biol Pharm Bull. 2005; 28:963-966.

Zhao X, Wang W, Zu Y, Zhang Y, Li Y, Sun W, Shan C, Ge Y. Preparation and characterization of betulin nanoparticles for oral hypoglycemic drug by antisolvent precipitation. Drug Delivery. 2014 $21: 467-479$

How to cite this article:

Echeverry SM, Valderrama IH, Costa GM, Ospina-Giraldo LF, Aragón DM. Development and optimization of microparticles containing a hypoglycemic fraction of calyces from Physalis peruviana. J App Pharm Sci, 2018; 8(05): 010-018. 